\title{
S-Nitrosylation of DRP1 Does Not Affect Enzymatic Activity and is Not Specific to Alzheimer's Disease
}

\author{
Blaise Bossy $^{\mathrm{a}}$, Alejandra Petrilli ${ }^{\mathrm{a}}$, Eva Klinglmayr ${ }^{\mathrm{b}}$, Jin Chen ${ }^{\mathrm{a}}$, Ursula Lütz-Meindl ${ }^{\mathrm{c}}$, \\ Andrew B. Knott ${ }^{\mathrm{a}}$, Eliezer Masliah ${ }^{\mathrm{d}}$, Robert Schwarzenbacher ${ }^{\mathrm{b}}$ and Ella Bossy-Wetzel ${ }^{\mathrm{a}, *}$ \\ ${ }^{a}$ Burnett School of Biomedical Sciences, College of Medicine, University of Central Florida, Orlando, FL, USA \\ ${ }^{\mathrm{b}}$ Structural Biology Group, Department of Molecular Biology, University of Salzburg, Austria \\ ${ }^{\mathrm{c}}$ Department of Cell Biology, University of Salzburg, Austria \\ ${ }^{\mathrm{d}}$ University of California San Diego, La Jolla, CA, USA
}

Accepted 10 April 2010

\begin{abstract}
Mitochondrial dysfunction and synaptic loss are among the earliest events linked to Alzheimer's disease (AD) and might play a causative role in disease onset and progression. The underlying mechanisms of mitochondrial and synaptic dysfunction in $\mathrm{AD}$ remain unclear. We previously reported that nitric oxide (NO) triggers persistent mitochondrial fission and causes neuronal cell death. A recent article claimed that S-nitrosylation of dynamin related protein 1 (DRP1) at cysteine 644 causes protein dimerization and increased GTPase activity and is the mechanism responsible for NO-induced mitochondrial fission and neuronal injury in $\mathrm{AD}$, but not in Parkinson's disease (PD). However, this report remains controversial. To resolve the controversy, we investigated the effects of S-nitrosylation on DRP1 structure and function. Contrary to the previous report, S-nitrosylation of DRP1 does not increase GTPase activity or cause dimerization. In fact, DRP1 does not exist as a dimer under native conditions, but rather as a tetramer capable of self-assembly into higher order spiral- and ring-like oligomeric structures after nucleotide binding. S-nitrosylation, as confirmed by the biotin-switch assay, has no impact on DRP1 oligomerization. Importantly, we found no significant difference in S-nitrosylated DRP1 (SNO-DRP1) levels in brains of age-matched normal, AD, or PD patients. We also found that S-nitrosylation is not specific to DRP1 because S-nitrosylated optic atrophy 1 (SNO-OPA1) is present at comparable levels in all human brain samples. Finally, we show that NO triggers DRP1 phosphorylation at serine 616, which results in its activation and recruitment to mitochondria. Our data indicate the mechanism underlying nitrosative stress-induced mitochondrial fragmentation in AD is not DRP1 S-nitrosylation.
\end{abstract}

Keywords: Large GTPases, mitochondrial fission and fusion, nitrosative stress, OPA1, SNO-DRP1, synapses

\section{INTRODUCTION}

Alzheimer's disease (AD) is the most common neurodegenerative disorder worldwide. Clinically, $\mathrm{AD}$ is a late-onset disease characterized by progressive loss of memory, language, and decision making skills due to

${ }^{*}$ Correspondence to: Ella Bossy-Wetzel, PhD, Burnett School of Biomedical Sciences, College of Medicine, 4000 Central Florida Blvd, Building 20, Orlando, Florida 32816, USA. Tel.: +1 (407) 823 3384; Fax: +1 (407) 823 0956; E-mail: ebossywe@ @ail.ucf.edu. loss of neurons in the hippocampus and cortex. Brain tissue of afflicted individuals exhibit two characteristic insoluble protein deposits: extracellular senile plaques composed primarily of amyloid- $\beta(\mathrm{A} \beta)$ peptide and intracellular neurofibrillary tangles consisting of hyperphosphorylated tau protein.

Oxidative stress from mitochondrial dysfunction is among the earliest changes in $\mathrm{AD}$. Oxidative damage precedes the appearance of senile plaques in $\mathrm{AD}$ patients and AD-like transgenic models [1-3]. Oxidative stress can exacerbate intracellular $\mathrm{A} \beta$ accumula- 
tion by activating signal transduction pathways that induce amyloid- $\beta$ protein precursor $(\mathrm{A} \beta \mathrm{PP})$ processing. Specifically, oxidative stress activates Jun aminoterminal kinase (JNK) and p38 mitogen-activated protein kinase (MAPK), which increases $\mathrm{A} \beta \mathrm{PP}$ processing [4]. Furthermore, mtDNA mutations have been found in $\mathrm{AD}$ brain tissue, which might contribute to reduced energy metabolism and exacerbated ROS production [5]. Axonal trafficking of mitochondria is also reduced in AD [6-8]. Finally, there is evidence that $\mathrm{A} \beta$ can directly injure mitochondria. For example, $\mathrm{A} \beta$ can block mitochondrial protein import and inhibit mitochondrial enzymes such as $\alpha$-ketoglutarate dehydrogenase and cytochrome $c$ oxidase [9-12]. A $\beta$ also forms abnormal protein complexes with mitochondrial proteins such as $\mathrm{A} \beta$-binding alcohol dehydrogenase (ABAD) or the serine protease OMI [13,14], both of which are thought to contribute to neuronal injury and cell death in AD.

Nitric oxide (NO) is an important neurotransmitter and neuromodulator and is produced in glia and neurons by enzymes called nitric oxide synthases (NOS). When generated in excess and under pathophysiological conditions, NO becomes neurotoxic by creating reactive nitrogen species (RNS) that can react with cysteine residues in proteins forming covalent thiol derivates (R-SNO). Such protein modification, known as S-nitrosylation, alters protein structure and function and can result in protein aggregation, a hallmark of many chronic neurodegenerative disorders. Nitrosative stress caused by RNS is not specific to AD but is thought to play an important role in many neurodegenerative disorders including Parkinson's disease (PD), Huntington's disease (HD), amyotrophic lateral sclerosis (ALS), and stroke [15]. Nitrosative stress in AD can originate from inflammation, glial cell activation, and cytokine release that activate inducible nitric oxide synthase (iNOS) or from accumulation of excitatory amino acids that over-stimulate glutamate receptors leading to neuronal nitric oxide synthase (nNOS) activation [15].

Neurons are highly dependent on mitochondrial function for energy supply. Mitochondria in neurons are dynamic and migrate, divide, and fuse. These processes are thought to facilitate energy distribution throughout neuronal projections and to sites of high energy demand such as synapses, to compensate for mtDNA mutations, to mix metabolites, and to maintain bioenergetic functionality. Mitochondrial fission and fusion is regulated by a family of large GTPases, with dynamin-related protein 1 (DRP1) directing fission and the mitofusins (MFN1, MFN2) and optic atrophy 1
(OPA1) directing fusion [16-23]. Excessive mitochondrial fission or insufficient mitochondrial fusion causes mitochondrial fragmentation, which decreases respiration and energy production, results in loss of mitochondrial membrane potential and mtDNA, and increases vulnerability to neuronal injury and cell death [24-26].

We previously showed that $\mathrm{A} \beta$ peptide induces mitochondrial fragmentation in cortical neurons [27], which was later confirmed by others [28]. Furthermore, using an animal model of acute ischemic brain injury we detected mitochondrial fragmentation prior to neuronal cell death in vivo. In addition, nitrosative stress is known to play an important role in ischemic stroke triggered mitochondrial fragmentation in isolated neurons $[27,29]$. Using time-lapse microscopy, we observed that the NO-induced mitochondrial fragmentation can be reversible and is insufficient to cause cell death. Thus, short-term NO-induced fragmentation and mitophagy might reflect a stress response to repair or eliminate damage and thereby increase cell survival $[27,29,30]$. However, long-term, persistent mitochondrial fragmentation results in bio-energetic failure, additional oxidative stress, and secondary activation of signaling pathways, all of which cause neuronal cell death $[27,29,30]$.

The precise mechanism underlying NO-induced mitochondrial fragmentation remains unclear. Expanding on our original line of investigation, a recent report proposed that S-nitrosylation of DRP1 increased DRP1 GTPase activity and was the mechanism of mitochondrial fragmentation in AD [31]. While this finding was of potentially great interest, the report raises several concerns in relation to previously published work in the field including the relative enzymatic activity of dominant negative mutant DRP1 ${ }^{K 38 A}$ and the oligomeric state of active DRP1. In addition, it is puzzling that all AD cases in this study exhibited elevated SNO-DRP1 levels while none of the PD or control cases did. Such a distribution is unusual for a sporadic disease like AD and would imply that SNO-DRP1 is the initiating event in all AD cases [31]. Finally, nitrosative stress is not specific to AD; therefore, it is a mystery why no SNODRP1 was observed in sporadic PD patient samples.

Because of these concerns and to reconcile the conflicting reports, we set out to investigate the effects of $\mathrm{NO}$ in AD. We found that, contrary to the previous report, S-nitrosylation of DRP1 does not alter GTPase activity. Furthermore, we found that DRP1 is mostly a tetramer both in vitro and in vivo that assembles into ring- and spiral-like structures under experimental conditions, independently of S-nitrosylation. In addition, 
we observed that S-nitrosylation of DRP1 was not specific to $\mathrm{AD}$ as human postmortem brain samples from PD and even normal patients exhibited comparable SNO-DRP1 levels. Furthermore, we also observed Snitrosylation of the mitochondrial fusion protein OPA1. In sum, our data indicate that S-nitrosylation of DRP1 is not the underlying mechanism of mitochondrial fragmentation in $\mathrm{AD}$ and we speculate that alternative pathways likely mediate the process.

\section{MATERIALS AND METHODS}

\section{Materials, chemicals, and antibodies}

Neocuproine, S-methyl methanethiosulfonate (MMTS), TBS/0.05\% Tween20, and sodium ascorbate were obtained from Sigma. NeutrAvidin agarose resin, N-[6-(biotinamide)hexyl]-3'-(2'-pyridyldithio) propionamide (EZ-Link Biotin-HPDP), SuperSignal West-Pico, -Dura, and -Femto chemiluminescent substrates were purchased from Thermo Scientific. $\mathrm{Nu}-$ PAGE LDS sample buffer, reducing agent, $\mathrm{Nu}-$ PAGE 4\%-12\% Bis-Tris gel, 3-12\% acrylamide NativePAGE $^{\mathrm{TM}}$ Novex Bis-Tris Gel System, Coomassie R-250, NativePAGE ${ }^{\mathrm{TM}}$ G-250 sample additive, and 1x NativePAGE sample buffer were purchased from Invitrogen. Hybond-ECL nitrocellulose membranes and ECL anti-mouse and anti-rabbit horseradish peroxidase conjugated IgG antibodies were purchased from GE Healthcare. Complete protease inhibitor cocktail was purchased from Roche. S-Nitrosylated Protein Detection Assay kit was purchased from Cayman Chemical Company. Mouse monoclonal antiDRP1 (clone 8/DLP1) and mouse monoclonal antiOPA1 (clone 18/OPA1) antibodies were purchased from BD Bioscience. Mouse anti-actin (clone JLA20) antibodies were purchased from Calbiochem. Rabbit anti-phospho-DRP1 Ser616 and anti-COX IV antibodies were purchased from Cell Signaling.

\section{Plasmids and recombinant proteins}

Human DRP1 cDNAs encoding the wild-type (699 amino acid muscle-expressed isoform, NCBI accession NM_005690.3, in pcDNA3 [23]) or mutant K38A were subcloned into the bacterial expression vectors pD13(pET30a) and pw12(pET17b), to create $80 \mathrm{kDa}$ recombinant proteins with a MGSSHHHHHHSSGLVPRGSH N-terminus tag. The recombinant proteins were purified with Ni-beads and a Superdex
S200 column and stored in $50 \mathrm{mM}$ Hepes $\mathrm{pH} 7.5$, $250 \mathrm{mM} \mathrm{NaCl}, 10 \%$ glycerol at $-70^{\circ} \mathrm{C}$. The human DRP1 cDNA (736 amino acid brain-specific isoform, NCBI accession NM_012062.3) was purchased from GeneCopoeia and subcloned into the baculovirus expression vector pFastBac (Invitrogen) to create an 84 $\mathrm{kDa}$ recombinant protein with a KGENLYFQGHHHHHH C-terminus tag. This recombinant protein was purified with Ni-beads, a Superdex S200 column, dialyzed and stored in $25 \mathrm{mM}$ Hepes, $25 \mathrm{mM}$ Pipes, $200 \mathrm{mM} \mathrm{NaCl}, \mathrm{pH} 7.0$ at $-70^{\circ} \mathrm{C}$.

\section{Postmortem brain tissue}

Human brain tissue from the frontal cortex of normal, AD, and PD (diffuse Lewy body disease) patients were from the Brain Bank of the Alzheimer's Disease Research Center, UCSD.

\section{GTPase assay}

Recombinant proteins were incubated for $10 \mathrm{~min}$ at room temperature in the dark with either $200 \mu \mathrm{M}$ fresh SNOC, aged SNOC, or left untreated. Fresh SNOC was prepared as described [32]. GTPase activity of $0.1 \mathrm{mg} / \mathrm{ml} \mathrm{DRP1} \mathrm{(699} \mathrm{aa} \mathrm{isoform)} \mathrm{was} \mathrm{mea-}$ sured with the continuous, regenerative coupled GTPase assay [33] and increasing GTP concentrations ( 0 , $10,20,30,60,100,150,250,500$, and $1000 \mu \mathrm{M})$. Absorbance $(340 \mathrm{~nm})$ was measured at $30^{\circ} \mathrm{C}$, pH 7.0 for 100 cycles of approximately 60 seconds per cycle with a FLUOstar Galaxy plate reader (BMG Labtechnologies). After plotting absorbance versus time, the steady state GTPase velocities and activities were calculated as described [33]. For analysis of the lag phase, the GTPase continuous assays were performed with $800 \mu \mathrm{M}$ NADH, $500 \mu \mathrm{M}$ GTP, $20 \mathrm{U} / \mathrm{ml}$ pyruvate kinase/lactate dehydrogenase, $1 \mathrm{mM}$ PEP, $5 \mathrm{mM} \mathrm{MgCl} \mathrm{Mg}_{2}$, $187.5 \mathrm{mM} \mathrm{NaCl}, 7.5 \mathrm{mM} \mathrm{KCl}$ in $25 \mathrm{mM}$ Hepes, 25 $\mathrm{mM}$ Pipes $\mathrm{pH} 7.0,30^{\circ} \mathrm{C}$.

\section{Biotin-switch assay of recombinant DRP1 protein}

After the GTPase assay, the DRP1 protein was collected from three wells of the 96-well plate and subjected to biotin-switch assay using a commercial kit. First, recombinant proteins were acetone precipitated and airdried. The blocking step was performed at $50^{\circ} \mathrm{C}$ for $20 \mathrm{~min}$. At the end only a small fraction (1/200) was separated on NuPAGE Novex 4-12\% Bis-Tris minigels without prior heating or DTT addition [34]. After immunoblotting, biotinylated proteins were detected with avidin-HRP and SuperSignal West-Pico chemiluminescent substrate. 


\section{Biotin-switch assay of human brain tissue}

To detect SNO-DRP1 in human brain, we used the biotin-switch assay as described [34,35]. Approximately $1 \mathrm{~g}$ of tissue was lysed in $13 \mathrm{ml}$ of HEN buffer plus Triton X-100 (250 mM Hepes pH 7.7, 1 mM EDTA, $0.1 \mathrm{mM}$ Neocuproine plus $1 \%$ Triton X-100) and homogenized with a $15 \mathrm{ml}$ Teflon-glass dounce and 10 strokes at $4^{\circ} \mathrm{C}$. Lysates were pre-cleared overnight with NeutrAvidin-agarose beads at $4{ }^{\circ} \mathrm{C}$. Free thiols were blocked with 2 volumes of blocking buffer $(40 \mathrm{mM}$ MMTS: methyl methanethiosulfonate, $2.5 \%$ SDS in HEN buffer) and incubated for $20 \mathrm{~min}$ at $50^{\circ} \mathrm{C}$. MMTS was removed by acetone precipitation and pellets were resuspended in HENS buffer (25 mM Hepes pH 7.7, $0.1 \mathrm{mM}$ EDTA, $10 \mu \mathrm{M}$ neocuproine, $1 \%$ SDS). Nitrosothiols were reduced to thiols with $1 \mathrm{mM}$ ascorbate and biotinylated with $4 \mathrm{mM} \mathrm{N}$-[6-(biotinamide)hexyl]3'-(2'-pyridyldithio)propionamide (Biotin-HPDP) labeling solution in dimethylformamide. Biotin-HPDP was removed by acetone precipitation and pellets were resuspended in HENS buffer. Biotinylated proteins were collected with NeutrAvidin agarose resin for $1 \mathrm{~h}$ at $4{ }^{\circ} \mathrm{C}$ under gentle agitation and washed five times with buffer (20 mM Hepes, $600 \mathrm{mM} \mathrm{NaCl}, 1 \mathrm{mM}$ EDTA, $0.5 \%$ TritonX-100). Biotinylated proteins were separated on NuPAGE Novex 4-12\% Bis-Tris minigels and SNO-DRP1 or SNO-OPA1 was detected by immunoblotting.

\section{Subcellular fractionation}

HEK293 cells were treated with $300 \mu \mathrm{M}$ SNOC for different time periods, scraped gently, and centrifuged at $200 \mathrm{~g}$ for $5 \mathrm{~min}$ at $4{ }^{\circ} \mathrm{C}$. The cell pellets were washed twice with cold PBS (pH 7.4) and resuspended with $500 \mu \mathrm{l}$ Buffer A $(250 \mathrm{mM}$ sucrose, $20 \mathrm{mM}$ Hepes, $\mathrm{pH} 7.4,10 \mathrm{mM} \mathrm{KCl}, 1.5 \mathrm{mM}$ EGTA, $1.5 \mathrm{mM}$ EDTA, $1 \mathrm{mM} \mathrm{MgCl}_{2}, 1 \mathrm{mM}$ dithiothreitol (DTT), $1 \mathrm{mM}$ $\mathrm{NaF}$, complete protease inhibitors). Cells were homogenized with a glass dounce and a B-type pestle for 50 strokes after $30 \mathrm{~min}$ incubation on ice. Nuclei and unbroken cells were removed as pellet after centrifugation at $800 \mathrm{~g}$ for $10 \mathrm{~min}$ at $4^{\circ} \mathrm{C}$. Supernatants were then centrifuged at $22,000 \mathrm{~g}$ for $15 \mathrm{~min}$ at $4{ }^{\circ} \mathrm{C}$, and the resulting supernatants were collected as cytosolic fractions. The mitochondrial pellets were resuspended with $200 \mu \mathrm{l}$ Buffer B [50 mM Hepes, pH 7.4, 1\% (v/v) NP-40, $10 \%$ (v/v) glycerol, $1 \mathrm{mM}$ EDTA, $2 \mathrm{mM}$ DTT, $1 \mathrm{mM} \mathrm{NaF}$, complete protease inhibitors] and incubated on ice for $20 \mathrm{~min}$. After centrifugation for $15 \mathrm{~min}$ at $22,000 \mathrm{~g}$ at $4{ }^{\circ} \mathrm{C}$, the supernatants containing mitochondria were stored as mitochondrial fractions.

\section{Immunoblotting}

Samples were separated with NuPAGE Novex 4$12 \%$ Bis-Tris minigels with or without reducing agent and transferred to a Hybond-ECL membrane $(0.45 \mu \mathrm{m}$ pores) for $2 \mathrm{~h}$ at 30 volts. Membranes were blocked with $5 \%$ nonfat milk in PBS or TBS with $0.05 \%$ Tween 20 for $3 \mathrm{~h}$ at room temperature and incubated with mouse anti-DRP1 (clone 8/DLP1) antibodies $(1: 1000)$ overnight at $4{ }^{\circ} \mathrm{C}$. After three washes, membranes were incubated for $1 \mathrm{~h}$ at room temperature with anti-mouse horseradish peroxidase-conjugated secondary antibodies (1:2000) in blocking solution. Immunocomplexes were detected using the SuperSignal West-Pico,-Dura, or-Femto chemiluminescent substrates. To detect SNO-OPA1, membranes from the biotin-switch assay were incubated with mouse monoclonal anti-OPA1 (1:1000) antibodies. To detect phospho-DRP1 Ser616 membranes were incubated with rabbit polyclonal anti-DRP Ser616 (1:1000) antibodies.

\section{Native gel electrophoresis}

Recombinant DRP1 was separated on 3-12\% Acrylamide NativePAGE ${ }^{\mathrm{TM}}$ Novex Bis-Tris Gel System and stained with either Coomassie R-250 or transferred to a PVDF membrane (Invitrolon ${ }^{\mathrm{TM}}$ ) following manufacturer's instructions (Invitrogen). Human brain extracts $(15 \mu \mathrm{g})$ were mixed with $0.34 \%$ NativePAGE ${ }^{\mathrm{TM}} \mathrm{G}-250$ sample additive and 1x NativePAGE sample buffer at room temperature and processed as described above.

\section{Transmission electron microscopy (TEM)}

Recombinant bacterial DRP1 protein (699 aa isoform) was diluted to $0.5 \mathrm{mg} / \mathrm{ml}$ in buffer (20 mM Hepes $\left.\mathrm{pH} 7.4,100 \mathrm{mM} \mathrm{NaCl}, 1 \mathrm{mM} \mathrm{MgCl}_{2}\right)$ and treated with or without fresh SNOC $(200 \mu \mathrm{M})$ for $10 \mathrm{~min}$ at room temperature and protected from light. To obtain oligomerization, protein samples were incubated with $1 \mathrm{mM}$ non-hydrolyzable GTP analog guanosine 5'-( $\beta$ - $\gamma$-imido) triphosphate (GMP-PNP) for about $3 \mathrm{~h}$ at room temperature. Samples were adsorbed to Formvar coated copper grids and negatively stained with $1 \%$ uranyl acetate. Electron micrographs were obtained using a LEO 912 transmission electron microscope (Zeiss) with an in-column spectrophotometer. The TEM was operated at $120 \mathrm{kV}$ and micrographs were acquired at zero energy loss filtering. 
Table 1

DRP1 GTPase activity per minute at three different GTP concentrations of the experiment shown in Fig. 1A. Values are $\pm \operatorname{SEM}(n=3)$

\begin{tabular}{cccccc}
\hline $\begin{array}{c}\text { GTP } \\
(\mathrm{mM})\end{array}$ & $\begin{array}{c}\text { DRP1 } \\
\text { Untreated } \\
\left(\mathrm{min}^{-1}\right)\end{array}$ & $\begin{array}{c}\text { DRP1 } \\
+ \text { aged SNOC } \\
\left(\mathrm{min}^{-1}\right)\end{array}$ & $\begin{array}{c}\text { DRP1 } \\
+ \text { SNOC } \\
\left(\mathrm{min}^{-1}\right)\end{array}$ & $\begin{array}{c}\text { DRP1 } \\
+ \text { aged SNOC } \\
\left(\mathrm{min}^{-1}\right)\end{array}$ & $\begin{array}{c}\text { DRP1 } \\
+ \text { SNOC } \\
\left(\mathrm{min}^{-1}\right)\end{array}$ \\
\hline 0.01 & $0.57 \pm 0.075$ & $0.561 \pm 0.085$ & $0.656 \pm 0.059$ & $0.0986 \pm 0.019$ & $0.104 \pm 0.011$ \\
0.15 & $1.69 \pm 0.118$ & $1.65 \pm 0.108$ & $1.62 \pm 0.148$ & $0.128 \pm 0.0072$ & $0.140 \pm 0.0148$ \\
1 & $2.17 \pm 0.325$ & $2.22 \pm 0.118$ & $2.15 \pm 0.014$ & $0.229 \pm 0.0194$ & $0.262 \pm 0.0825$ \\
\hline
\end{tabular}

\section{RESULTS}

\section{S-nitrosylation has no effect on DRPI GTPase activity}

A recent report claimed that S-nitrosylation increases DRP1 GTPase activity and is the mechanism responsible for mitochondrial fragmentation, bioenergetic compromise, and synaptic damage in a cellular model of $\mathrm{AD}$ [31]. However, the article conflicts with previous work. First, the authors investigated whether Snitrosylation of DRP1 affects its GTPase activity. However, they mistakenly equated absorbance at a single time point and one GTP concentration with enzyme activity instead of determining a steady state activity with multiple time points and substrate concentrations. Second, the GTPase-defective dominant negative DRP1 ${ }^{K 38 A}$ mutant, which was previously shown as having very low if any enzymatic activity, is a critical negative control for DRP1 activity determination [36]. However, Cho et al. reported an unexpected DRP $1^{K 38 \mathrm{~A}}$ absorbance (used as an indicator of activity) that was more than half as great as wild-type DRP1, which casts doubts on the validity of their GTPase assay [31]. Based on this assay, the authors proposed a two-fold increase in DRP1 GTPase activity upon S-nitrosylation at cysteine 644, a cornerstone of their report.

To get to the bottom of these contradictory findings, we investigated the effect of S-nitrosylation on recombinant bacterial DRP1 using nine GTP concentrations and more than eighty time points to determine the steady state accurately. Wild-type DRP1 protein or the dominant negative mutant DRP1 ${ }^{K 38 A}$ were left untreated or treated with fresh $\mathrm{NO}$ donor S-nitrocysteine (SNOC) or aged SNOC control, in which all NO was released due to its instability. As shown in Fig. 1A and summarized in Table 1, neither fresh nor aged SNOC increased DRP1 GTPase activity. In our experiments, DRP $1^{K 38 A}$ exhibited the expected 5 to 15 -fold reduction in GTPase activity compared to wild-type DRP1 protein indicating that our GTPase assay does not harbor any artifacts. To test whether DRP1 S-nitrosylation reduces the lag phase of enzyme activity before steady state, we measured the initial rate of GTP hydrolysis after DRP1 was exposed to either aged or fresh SNOC. As shown in Fig. 1C, we did not observe a change in the lag phase of DRP1 GTP hydrolysis. It could be argued that our recombinant DRP1 protein was already maximally oxidized. In such a scenario, the protein cysteines might already be modified, preventing their S-nitrosylation by NO donors, and thereby providing an explanation for the lack of detectable increased DRP1 activity. To rule out this possibility, we tested whether the same DRP1 protein we used in our GTPase assay was indeed S-nitrosylated using the biotin-switch assay, an assay which detects S-nitrosylated proteins. In the biotin-switch assay, nitrosylated cysteines are converted into biotinylated cysteines. Using this assay, we readily detected SNO-DRP1, which would not have been possible if DRP1 was oxidized during the protein isolation (Fig. 1B). Similar results were obtained with several independent bacterial as well as baculovirus protein preparations. In sum, our data provides strong evidence that S-nitrosylation of DRP1 does not increase its GTPase activity.

\section{DRP1 is mostly a tetramer under native conditions}

The recent article by Cho et al. proposed that Snitrosylation of cysteine 644 enhances GTP hydrolysis via DRP1 dimerization [31]. However, this is in stark disagreement with the current mammalian DRP1 literature $[37,38]$. There are no reports that support a dimer-stimulated DRP1 activation. Instead, cross linking and gel filtration studies have shown that DRP1 is a tetramer and that self-assembly into higher order oligomers, rings, and spirals stimulates GTP hydrolysis [37,38]. Therefore, DRP1 dimerization would reflect the opposite, disassembly and decreased GTP hydrolysis.

To resolve this apparent contradiction, we performed native gel electrophoresis of two bacterial DRP1 protein isoforms before treatment or after treatment with either aged or fresh SNOC. The first isoform is 699 amino acids, expressed predominantly in muscle, and 

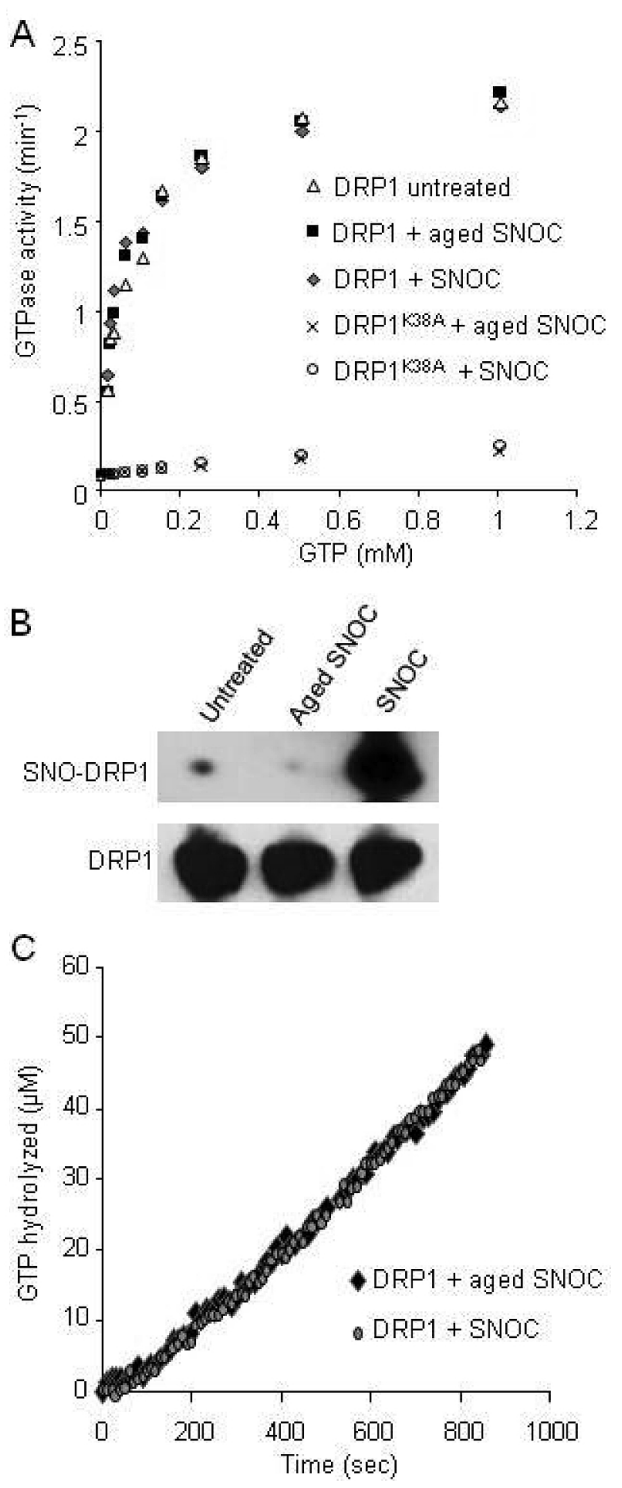

Fig. 1. S-Nitrosylation of DRP1 does not alter GTPase activity. A) Kinetics of DRP1 GTPase activity. Recombinant wild-type DRP1 or mutant DRP1 ${ }^{K 38 A}$ were pre-treated with either $200 \mu \mathrm{M}$ of fresh SNOC, aged (decayed) SNOC, or left untreated and then subjected to the GTPase assay. Data indicate mean steady state values $(n=3)$. B) Detection of SNO-DRP1. Biotin-switch assay of the DRP1 protein after the GTPase assay of the experiment shown in (A). Proteins were separated by SDS-PAGE and immunoblots were probed with either avidin-horseradish peroxidase for detection of SNO-DRP1 (top) or with anti-DRP1 antibodies (bottom). C) Initial rate of GTP hydrolysis at $500 \mu \mathrm{M}$ GTP in the presence of DRP1 pretreated with either $200 \mu \mathrm{M}$ fresh or aged SNOC.

used by Cho et al. [31], and the second isoform is 736 amino acids and brain-specific. Both DRP1 isoforms were fused with a polyhistidine tag used for purification. In all cases, DRP1 migrated mostly as a tetramer or a higher molecular weight unit thereof (Fig. 2A). Importantly, SNO-DRP1 (Fig. 2A, lane 3 and 6) did not exhibit greater assembly into higher molecular weight tetrameric units when compared to DRP1 either untreated or treated with aged SNOC (Fig. 2A, lane 1, 2 and 4, 5 respectively). Furthermore, addition of reducing agent dithiothreitol (DTT) at room temperature did not alter the tetramers (Fig. 2B). Thus, DRP1 is predominantly a tetramer or higher order oligomer in its native condition and S-nitrosylation of DRP1 has no effect on its oligomerization state. Finally, we found that DRP1 is present mostly as a tetramer in three groups of three human postmortem brain samples of normal, $\mathrm{AD}$, and $\mathrm{PD}$ patients (Fig. 2C), confirming our in vitro data with recombinant protein and previous cell line studies [37,38].

Cho et al. reported that S-nitrosylation of cysteine 644 increases DRP1 disulfide-linked dimerization using SDS-PAGE in the absence of reducing agent DTT [31]. It is puzzling to us how SNO-DRP1 could undergo the alleged disulfide-linked dimerization considering that the critical cysteine (Cys644) is reportedly blocked by S-nitrosylation. To explore this further, we performed SDS-PAGE of DRP1 and SNO-DRP1 in the presence or absence of DTT. Using SDS-PAGE, we show that under these denaturing conditions both DRP1 and SNO-DRP1 exhibit monomers and dimers in the absence of DTT, which are released only as monomers in the presence of DTT (Fig. 2D). Thus, dimerization under denaturing conditions does not depend on S-nitrosylation. In summary, our data do not support a dimer-mediated DRP1 activation model as proposed by Cho et al. and are in strong agreement with the current literature indicating that DRP1 is mostly a tetramer and higher order oligomerization promotes GTP hydrolysis.

\section{S-nitrosylation does not stimulate DRP1 self-assembly}

Similar to yeast DNM1, human DRP1 assembles into higher order oligomers, forming curved filaments and occasional rings in the presence of low salt conditions or rings and spiral-like structures in the presence of non-hydrolyzable nucleotides [23,39]. To test whether S-nitrosylation of DRP1 increases its ability to self-assemble, which would be consistent with increased activation, we used negative stain and transmission electron microscopy to visualize oligomerization. We found that DRP1 and SNO-DRP1 assemble into similar large spiral-like structures in the presence of the non-hydrolyzable GTP analogue guanosine GMP- 

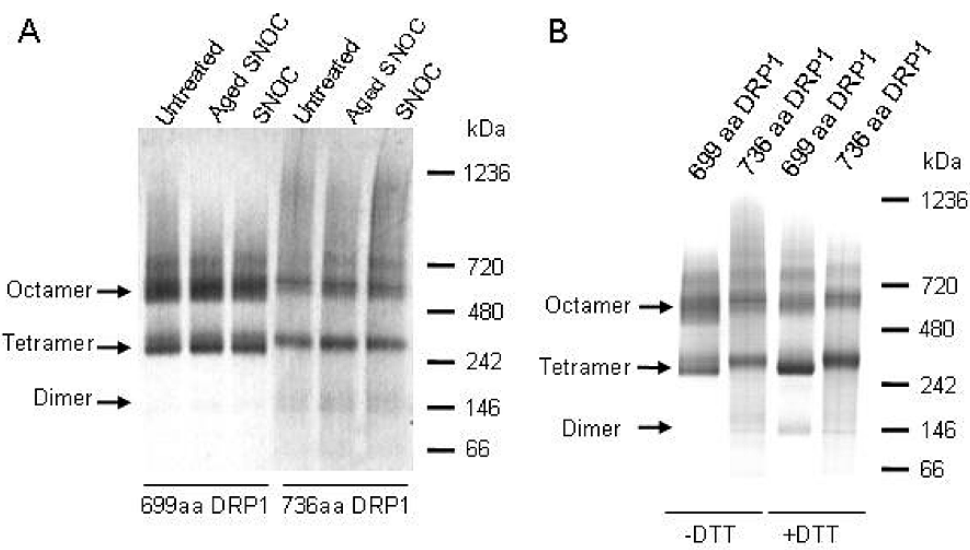

$\mathrm{C}$
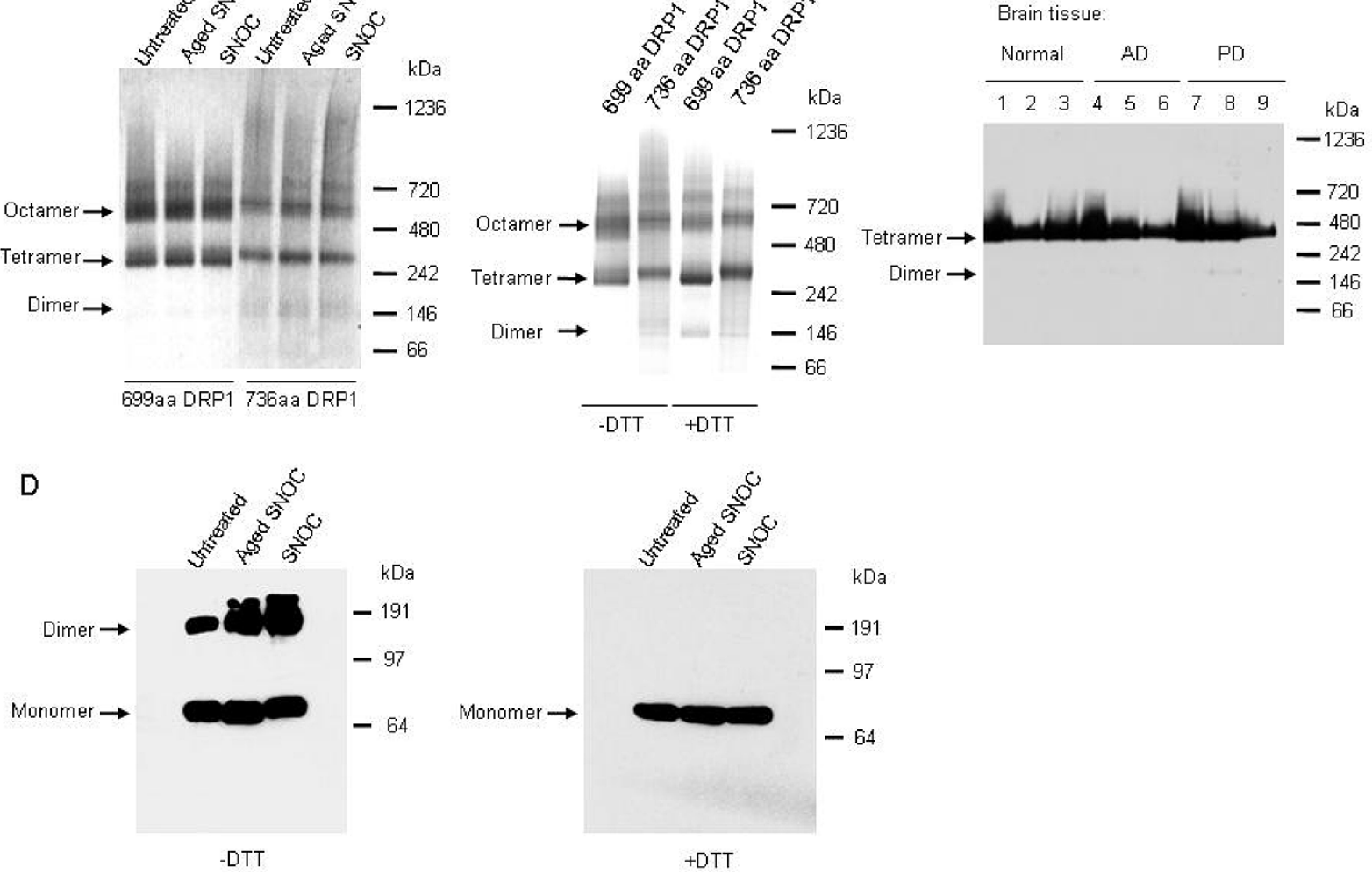

Fig. 2. Recombinant and brain DRP1 form tetramers under native conditions irrespective of S-nitrosylation. A) DRP1 runs as tetramer or higher order oligomer in native gels. Recombinant DRP1 isoforms were left untreated or pre-treated with aged or fresh SNOC (200 $\mu \mathrm{M})$, separated on native gels and stained with Coomassie blue. B) Reducing conditions do not break the tetramers in native gels. Recombinant DRP1 isoforms were separated under non-reducing (-DTT) or reducing conditions (+DTT) on native gels and Coomassie blue stained. C) Human brain DRP1 is mostly a tetramer. Brain extracts from normal controls (lanes 1, 2, 3), AD (lanes 4, 5, 6) or PD patients (lanes 7, 8, 9) were separated on native gels and immunoblots were probed with anti-DRP1 antibodies. D) S-nitrosylation of DRP1 does not trigger DRP1 dimerization. Recombinant DRP1 (699 amino acid isoform) was left untreated or treated with aged or fresh SNOC (200 $\mu \mathrm{M})$, heat denatured under non-reducing (-DTT) or reducing conditions (+DTT) and separated by SDS-PAGE, immunoblotted, and probed with anti-DRP1 antibodies.

PNP (Fig. 3A and 3B). Similarly, in low salt conditions and in the absence of nucleotides, curved filaments and rings were observed both with DRP1 and SNO-DRP1 (Fig. 3C and 3D). Thus, S-nitrosylation did not enhance DRP1 oligomerization. Of note is that the diameter of the rings was about $35 \mathrm{~nm}$, similar to previously described human DRP1 rings [23], which is smaller than the $110 \mathrm{~nm}$ diameter of DNM1 rings [40].

\section{SNO-DRP1 is not increased in the AD brain}

Using the biotin-switch assay to detect S-nitrosylated proteins, SNO-DRP1 was reported to be increased in brain tissue of $\mathrm{Tg} 2576 \mathrm{AD}$ mice and AD patients [31]. However, important controls were missing in the original report. To test whether SNO-DRP1 levels are indeed increased in $\mathrm{AD}$, brain tissue lysates of normal age-matched individuals and AD and PD patients were prepared and subjected to the biotin-switch assay. Our samples were obtained from the same brain bank as some, if not all, of the samples described by Cho et al. To remove endogenously biotinylated proteins that interfere with the biotin-switch assay, we pre-cleared the brain extracts with NeutrAvidin agarose beads. Unexpectedly, we found biotinylated DRP1 protein in all brain samples (Fig. 4A). Thus, a small fraction of DRP1 is modified by biotinylation in aged individuals. When running the pre-cleared brain lysates we found reduced DRP1 protein in the AD patient relative to the normal sample (Fig. 4B), which is consistent with previous reports [41].

We next used the NeutrAvidin agarose pre-cleared extracts in the three step biotin-switch assay. In the first step, the free R-SH groups are blocked by $\mathrm{S}$ methylation. In the second step, ascorbate is used to reduce the R-SNO groups to $\mathrm{R}-\mathrm{SH}$. In the third step, the 

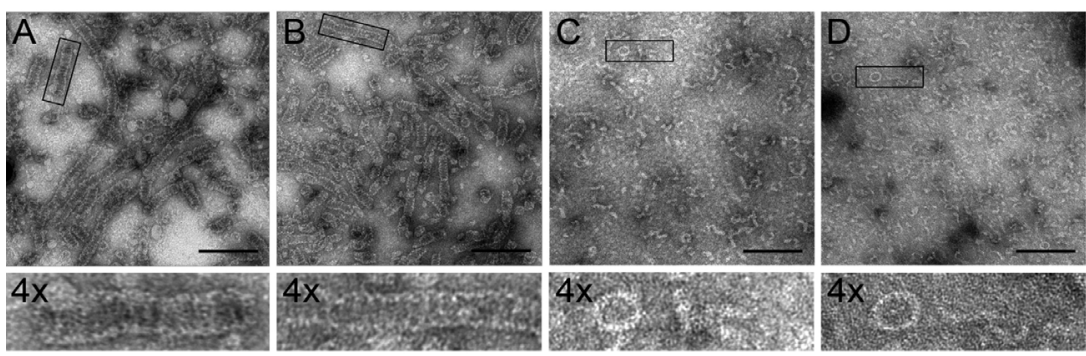

Fig. 3. S-Nitrosylation has no effect on DRP1 assembly. Electron micrographs of negatively stained recombinant DRP1 (699aa isoform) in the presence of non-hydrolyzable GTP analog GMP-PNP and corresponding 4x zoom of regions of interest (A) - SNOC and (B) + SNOC. C) Control at $100 \mathrm{mM} \mathrm{NaCl}$ with neither nucleotide nor SNOC. D) Control at $100 \mathrm{mM} \mathrm{NaCl}$ with $200 \mu \mathrm{M}$ SNOC without nucleotide. Scale bar, $200 \mathrm{~nm}$.

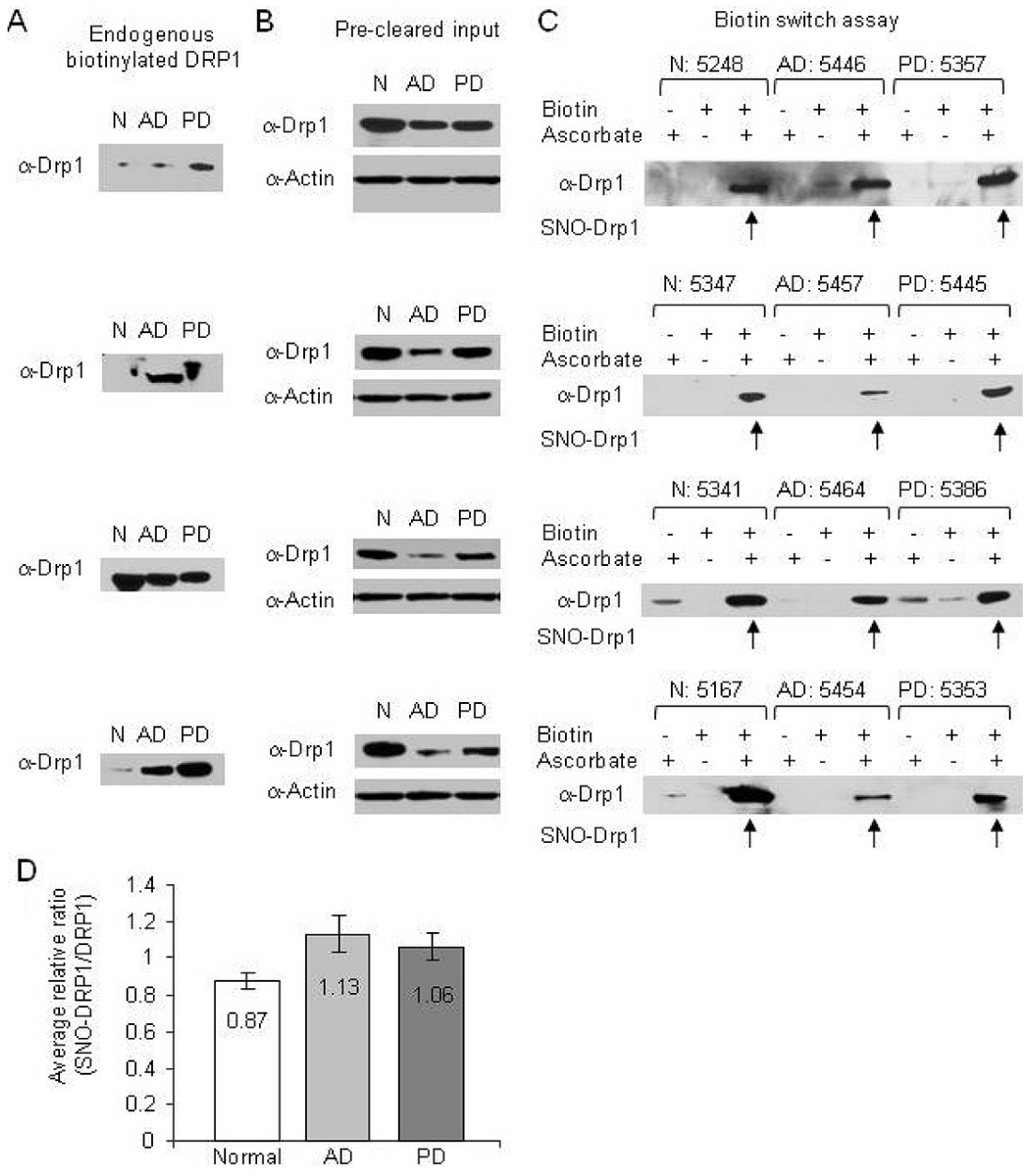

Fig. 4. SNO-DRP1 is not specific to AD. A) DRP1 is endogenously biotinylated. Immunoblot of NeutrAvidin agarose from normal (N), AD or PD human brain lysates probed with anti-DRP1 antibodies. B) Immunoblots of pre-cleared input brain DRP1 protein used in the biotin-switch assay, with actin serving as loading control. C) SNO-DRP1 (arrows) in human normal, AD, or PD brain including the biotin and ascorbate controls using the biotin-switch assay and DRP1 immunoblotting. ID number of postmortem samples is indicated above each blot. D) Ratios of SNO-DRP1 to DRP1 in normal $(n=4), \mathrm{AD}(n=4)$, and $\mathrm{PD}(n=4)$ brain samples. Ratios were calculated from densitometric values using the ImageJ Gel Analysis software. The SNO-DRP1 signals were corrected for the signals obtained in ascorbate controls. Data are \pm S.E.M. 


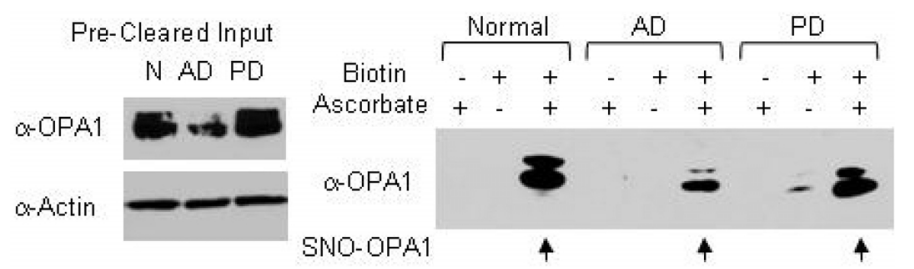

Fig. 5. Presence of SNO-OPA1 in normal, AD, and PD brains. Immunoblot of input proteins used in the biotin-switch assay probed with anti-OPA1 or anti-Actin controls (left panels). SNO-OPA1 (arrows) in human normal (N), AD, or PD brain, including the biotin and ascorbate controls, was detected by the biotin-switch assay and OPA1 immunoblotting (right panel).

newly formed R-SH groups are biotinylated, the R-S$\mathrm{S}$-biotin proteins are collected by incubation with NeutrAvidin agarose resin, and bound proteins are separated by SDS-PAGE. As shown in Figure 4C, omission of the biotinylating agent in the presence of ascorbate revealed little or no endogenously biotinylated DRP1 protein left after pre-clearing. Furthermore, omission of ascorbate and prevention of R-SNO reduction indicated that most free R-SH groups were effectively blocked by S-methylation. Finally, performing all steps of the biotin-switch assay revealed SNO-DRP1 (Fig. 4C). However, contrary to the previous report we found no consistent increase in SNO-DRP1 levels in the AD patient samples. The PD and even normal patient samples exhibited comparable SNO-DRP1 levels. We also found no evidence for a significant increase in the ratio of SNO-DRP1 to DRP1 in AD patients (Fig. 4D). In summary, our data suggest that DRP1 S-nitrosylation is not specific to $\mathrm{AD}$, but occurs in all aged individuals.

\section{SNO-OPAl is found in the human brain}

To determine whether other proteins associated with mitochondrial fission and fusion might be targets of Snitrosylation, we re-examined the human postmortem brain samples for signs of S-nitrosylation of OPA1, a mitochondrial fusion factor localized to the mitochondrial inner membrane. The biotin-switch assay of normal, AD, and PD patient samples all indicated the presence of SNO-OPA1 (Fig. 5). Thus, it appears that DRP1 is not the only mitochondrial fission/fusion GTPase that is S-nitrosylated in the human brain. However, we also found, similar to a previous report, that OPA1 protein levels were reduced in the AD sample [41]. Whether S-nitrosylation of OPA1 modifies its function remains to be determined.

\section{NO triggers DRP1 phosphorylation and recruitment to mitochondria}

Because S-nitrosylation does not increase DRP1 activity and is therefore not the mechanism underlying
NO-mediated mitochondrial fission, we speculated that NO stress might activate kinases, which in turn phosphorylate and activate DRP1. There is evidence that NO stress activates several kinases that participate in NO-mediated neuronal injury and cell death [42]. Furthermore, cdk1 phosphorylates DRP1 at serine 616, which allows translocation of DRP1 to mitochondria and stimulates mitochondrial fission $[43,44]$. Interestingly, several cell cycle kinases are abnormally elevated in $\mathrm{AD}$, a phenomenon that is thought to cause an abortive cell cycle entry and neuronal cell death [42, 45]. To test whether NO induces cdk1-mediated DRP1 phosphorylation, we exposed HEK293 cells to either aged or fresh SNOC and isolated the cytosolic and mitochondrial fraction at various time points. Immunoblotting using a phospho-DRP1 Ser616 specific antibody revealed a rapid increase of cytosolic phospho-DRP1 Ser616 after one hour of SNOC exposure, which was followed by an accumulation of phospho-DRP1 Ser616 at mitochondria after three hours of SNOC exposure (Fig. 6A). To test whether this observation might be of relevance to human $\mathrm{AD}$, we determined the ratio of phospho-DRP1 Ser616 to DRP1 of five groups of normal, AD, and PD brain samples (summarized in Table 2). Figure 6C shows that there is a trend of increased phospho-DRP1 Ser616 in AD samples, although it was not a statistically significant difference relative to normal samples. These results are consistent with a previous report indicating an increase in phospho-DRP1 Ser616 in the AD brain [41]. Thus, our data suggest that NO stress induces rapid DRP1 phosphorylation at serine 616 and activates mitochondrial fission, offering an alternative mechanism of NO-mediated mitochondrial fragmentation in AD.

\section{DISCUSSION}

A recent study proposed that S-nitrosylation of DRP1 in AD induces mitochondrial fission by a dimermediated increase in GTPase activity and results in 
Table 2

Human brain samples analyzed in this study. AD: Alzheimer's disease, PD: Parkinson's disease, M: male, F: female, PMH: postmortem hours, nd: not done

\begin{tabular}{|c|c|c|c|c|c|c|c|c|c|c|}
\hline Patient & $\begin{array}{l}\text { Fig 2C } \\
\text { lane \# }\end{array}$ & $\begin{array}{l}\text { Fig 6B } \\
\text { lane \# }\end{array}$ & $\begin{array}{c}\text { Fig } 5 \\
\text { samples }\end{array}$ & Diagnosis & $\begin{array}{c}\text { Age } \\
\text { (years) }\end{array}$ & PMH & Gender & $\begin{array}{l}\text { SNO- } \\
\text { DRP1 }\end{array}$ & \begin{tabular}{l}
\multicolumn{1}{c}{ Relative } \\
ratio SNO-DRP1/ \\
DRP1 for Fig 4C
\end{tabular} & $\begin{array}{c}\text { Relative } \\
\text { ratio phospho-DRP1/ } \\
\text { DRP1 for Fig 6B }\end{array}$ \\
\hline 5130 & & & & Normal & 71 & 2 & $\mathrm{M}$ & + & nd & nd \\
\hline 5347 & & 1 & Normal & Normal & 86 & & M & + & 0.818 & 0.576 \\
\hline 5248 & & 4 & & Normal & 93 & 18 & $\mathrm{~F}$ & + & 0.866 & 1.018 \\
\hline 5341 & 3 & 2 & & Normal & 77 & 12 & $\mathrm{~F}$ & + & 0.810 & 0.609 \\
\hline 5167 & 1 & 5 & & Normal & 83 & & M & + & 0.987 & 1.257 \\
\hline 5404 & & & & $\mathrm{AD}$ & 82 & 10 & M & + & nd & nd \\
\hline 5391 & & & & $\mathrm{AD}$ & 91 & 6 & M & + & nd & nd \\
\hline 5276 & & & & $\mathrm{AD}$ & 93 & 5 & M & + & nd & nd \\
\hline 5457 & & 8 & $\mathrm{AD}$ & $\mathrm{AD}$ & 77 & 8 & M & + & 0.934 & 1.282 \\
\hline 5446 & & 7 & & $\mathrm{AD}$ & 90 & 12 & $\mathrm{~F}$ & + & 0.998 & 3.789 \\
\hline 5464 & 6 & 6 & & $\mathrm{AD}$ & 73 & 9 & M & + & 1.372 & 1.534 \\
\hline 5454 & 4 & 9 & & $\mathrm{AD}$ & 71 & 12 & M & + & 1.216 & 0.634 \\
\hline 5445 & & 12 & PD & PD & 86 & 12 & M & + & 1.272 & 0.586 \\
\hline 5357 & & 14 & & PD & 94 & 12 & M & + & 1.050 & 1.349 \\
\hline 5386 & 9 & 13 & & PD & 74 & 27 & M & + & 1.005 & 1.102 \\
\hline 5353 & 7 & 15 & & PD & 78 & 12 & M & + & 0.917 & 1.033 \\
\hline 5302 & 2 & 3 & & Normal & 83 & 72 & M & nd & nd & 0.470 \\
\hline 5451 & 5 & 10 & & $\mathrm{AD}$ & 71 & 8 & M & nd & nd & 1.190 \\
\hline 5216 & 8 & 11 & & PD & 74 & & M & nd & nd & 1.255 \\
\hline
\end{tabular}

bioenergetic failure, synaptic loss, and neuronal injury characteristic of the disease [31]. Here we provide strong evidence contesting this claim. First, we show that S-nitrosylation does not increase the GTPase activity of DRP1. We arrived at this conclusion using two independent GTPase assays, the continuous assay (Fig. 1A) and malachite green-based assay (unpublished results), and several independent bacterial and baculovirus DRP1 protein preparations. Second, we find that S-nitrosylation of DRP1 does not cause dimerization or activation. In fact, most recombinant DRP1 and human brain DRP1 do not exist as monomers and dimers under native conditions, but rather as tetramers or higher order oligomer thereof. This finding is in agreement with the mammalian DRP1 literature [37, 38]. Third, we show that S-nitrosylation of DRP1 does not enhance assembly into oligomeric spiral-like structures. Fourth, SNO-DRP1 is not increased in the postmortem human AD brain and is also readily detected in PD brain and even normal brain. Finally, we demonstrate that S-nitrosylation is not specific to DRP1 as the mitochondrial fusion GTPase OPA1 also undergoes S-nitrosylation.

In evaluating our data, it is critical to point out that the recombinant DRP1 protein we used was not overoxidized. The following observations argue against this claim. First, we easily detected SNO-DRP1 with the biotin-switch assay. Thus, over-oxidation and consequent failure to S-nitrosylate DRP1 did not occur. Second, mass spectrometry did not reveal any hints of oxi- dation (unpublished results). Third, our protein is fully functional and able to form spiral-like structures. Collectively, our data strongly indicate that the mechanism underlying NO-mediated mitochondrial fragmentation in $\mathrm{AD}$ and likely other neurodegenerative disorders is not DRP1 S-nitrosylation. Additional investigations are needed to unravel the mechanism of NO-mediated mitochondrial fragmentation.

Excess NO mediates cell death by inhibiting multiple metabolic and cellular pathways, all of which could cause mitochondrial fragmentation and morphology changes. For example, NO and peroxynitrite are potent inhibitors of the mitochondrial respiratory chain [4648]. Thus, NO-mediated respiratory inhibition, similar to inhibition caused by rotenone or 3-NP, might elicit mitochondrial fragmentation [27,30]. Alternatively, NO might break down the cytoskeleton and microtubule organization, which could detach mitochondria from motor proteins and microtubule fibers, resulting in conversion of mitochondrial morphology to the more rounded phenotype, arrest in trafficking of mitochondria along axons and dendrites, and ultimately a decline in mitochondrial fusion. Defects in cytoskeletalmediated axonal organelle trafficking have been observed in AD [6].

Another possible mechanism of NO-mediated mitochondrial fragmentation in $\mathrm{AD}$ is that peroxynitrite nitrates tyrosines in the peroxisome proliferator-activated receptor gamma (PPAR $\gamma$ ), preventing its translocation from the cytoplasm to the nucleus and thus prevent- 
A
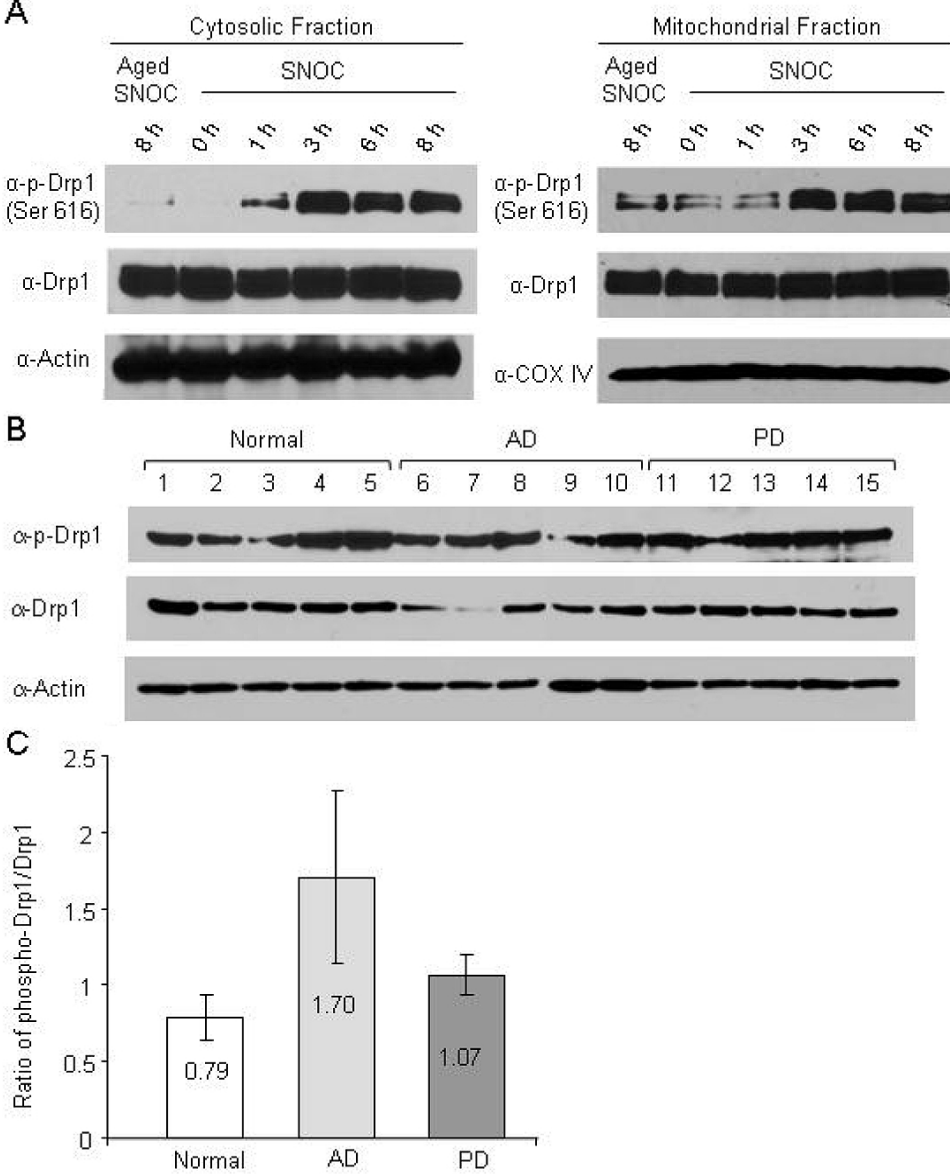

Fig. 6. NO triggers DRP1 Ser616 phosphorylation and recruitment to mitochondria. A) Immunoblots of Ser616 phosphorylated DRP1 and total DRP1 in the cytosolic or mitochondrial fractions. Actin and COX IV were used as loading controls and markers for the cytosolic and mitochondrial fractions, respectively. HEK293 cells were exposed either to aged or fresh SNOC $(300 \mu \mathrm{M})$ and the cytosolic and mitochondrial fractions were isolated after various time points. B) Immunoblots of phospho-DRP1 (upper panel), total DRP1 (middle panel) and actin (lower panel) in human normal, AD, or PD brain samples. C) Ratios of p-DRP1 Ser616 to DRP1 of normal $(n=5), \operatorname{AD}(n=5)$, or PD $(n=5)$ brains. Ratios were obtained by densitometric measurements of immunoblots using the ImageJ Gel Analysis software. Samples were normalized with the actin loading control.

ing mitochondrial biogenesis [49]. PPAR $\gamma$ is a nuclear hormone receptor which regulates mitochondrial biogenesis by increasing expression of nuclear respiratory factor (NRF) and mitochondrial transcription factor A (mtTFA). Both factors increase the expression of nuclear and mitochondrial genes that encode components of the respiratory chain, antioxidant defense mechanism, and mitochondrial DNA replication system. PPAR $\gamma$ expression has been shown to protect neurons from $\mathrm{A} \beta$ mediated toxicity [50]. Interestingly, MFN2 is regulated by PPAR $\gamma$. Hence, peroxynitrite-mediated inhibition of PPAR $\gamma$ and mitochondrial biogenesis might contribute to bio-energetic defects and an imbalance in expression of mitochondrial fission and fusion GTPases.
Nitrosative stress activates kinases that in turn might phosphorylate DRP1 resulting in its activation [44]. For example, p38MAP kinase is activated by peroxynitrite [51] and DRP1 phosphorylation by Cdk1/cyclinB at serine 616 promotes mitochondrial fission in mitotic cells [44]. We show here that DRP1 is rapidly phosphorylated at serine 616 and recruited to mitochondria upon exposure to the NO donor SNOC. Whether Cdk1/cyclinB is the serine kinase that mediates the NO effect remains unclear; however, activation of cell cycle kinases including Cdk1/cyclinB is thought to participate in AD pathogenesis [42]. In addition, a recent study reported DRP1 Ser616 phosphorylation in the cytosolic and mitochondrial fraction of the AD patient brain [41]. Another kinase that might 
get activated by nitrosative stress is $\mathrm{Ca}^{2+}$ /calmodulindependent kinase I $\alpha(\mathrm{CaMKI} \alpha)$. NO blocks mitochondrial respiration, which could lead to a decline in energy metabolism, inhibition of the $\mathrm{Na}^{+} / \mathrm{K}^{+}$ATPase pump, plasma membrane depolarization, and activation of voltage-dependent $\mathrm{Ca}^{2+}$ channels (VDCC). An impaired $\mathrm{Ca}^{2+}$ homeostasis has been reported in AD [52]. Activation of VDCC by elevated extracellular $\mathrm{K}^{+}$was found to increase intracellular $\mathrm{Ca}^{2+}$ levels and to activate $\mathrm{CaMKI} \alpha$ kinase, which in turn phosphorylates DRP1 at serine 600 causing increased binding to Fis 1 and mitochondrial fragmentation in neurons and other cell types [53]. Yet another scenario is that altered $\mathrm{Ca}^{2+}$ homeostasis might cause activation of the $\mathrm{Ca}^{2+}$-dependent phosphatase calcineurin, which dephosphorylates DRP1 at specific sites and causes its activation $[54,55]$.

Last, nitrosative and oxidative stress may cause processing, misfolding, oligomerization, and accumulation of $\mathrm{A} \beta$ peptide in mitochondria. Whether toxic $\mathrm{A} \beta$ oligomers can abnormally interact with mitochondrial fission and fusion factors like DRP1, OPA1, or MFN2 has not been tested; however, abnormal $\mathrm{A} \beta$ interaction with mitochondrial proteins has been documented and is thought to contribute to AD pathogenesis [56,57].

The pathways here are just a few potential mechanisms that might account for NO-mediated mitochondrial fragmentation in $\mathrm{AD}$, which underscores the pleiotropic nature of the cellular responses to nitrosative stress. Thus, it is very unlikely that NO mediates mitochondrial fragmentation by directly modulating a single protein target such as DRP1. Accordingly, while Cho et al. showed that the DRP1 C644A mutant, in which the critical cysteine has been mutated preventing S-nitrosylation, still induces mitochondrial fragmentation as strongly as wild-type DRP1, it appeared to prevent NO-mediated cell death by a mechanism distinct from dominant negative interference. It is difficult to envision how this mutant could mediate neuronal survival while still inducing mitochondrial fragmentation.

Furthermore, whether mitochondrial fragmentation is the cause or consequence of the bio-energetic defects and the synaptic loss in AD remains to be shown. Presently, not a single in vivo study has conclusively demonstrated that mitochondrial fragmentation occurs early in AD and is the primary event causing mitochondrial defects and synaptic changes. In fact, all data are based on overexpression systems or treatment of cultured cells with $\mathrm{A} \beta$. In addition, existing studies have produced conflicting results. For example, human fibroblasts of $\mathrm{AD}$ patients show the opposite phenotype, more elongated and fewer mitochondria, of that observed in human brain tissue, cultured neurons, and animal models [58].

It is plausible that in $\mathrm{AD}$ the bioenergetic defects are primarily the result of other mechanisms including $\mathrm{Ca}^{2+}$ overload, mitochondrial permeability transition and loss of mitochondrial membrane potential, nitrosative or oxidative stress and inhibition of key mitochondrial enzymes, and direct interference of toxic oligomeric $\mathrm{A} \beta$ with mitochondrial function and transport, with impaired mitochondrial fission and fusion being a secondary event. For example, only mitochondria that have a high mitochondrial membrane potential can fuse and mitochondria with low potential are selectively degraded by mitophagy. Thus, the hypothesis that the mitochondrial defects in a sporadic neurodegenerative conditions like AD are the result of a dysfunction in the fission/fusion machinery is premature and likely too simplistic [59] and would require more conclusive experimental support using appropriate in vivo models.

\section{ACKNOWLEDGMENTS}

We thank Dr. A.M. van der Bliek (UCLA) for the human WT-DRP1 and DRP $1^{K 38 A}$ cDNAs that encode the 699 amino acid DRP1 isoform. This work is supported by NIH grants R01EY016164 and R01NS055193 to EBW.

Authors' disclosures available online (http://www.jalz.com/disclosures/view.php?id=409).

\section{REFERENCES}

[1] Lu T, Pan Y, Kao SY, Li C, Kohane I, Chan J, Yankner BA (2004) Gene regulation and DNA damage in the ageing human brain. Nature 429, 883-891.

[2] Nunomura A, Perry G, Aliev G, Hirai K, Takeda A, Balraj EK, Jones PK, Ghanbari H, Wataya T, Shimohama S, Chiba S, Atwood CS, Petersen RB, Smith MA (2001) Oxidative damage is the earliest event in Alzheimer disease. J Neuropathol Exp Neurol 60, 759-767.

[3] Pratico D, Uryu K, Leight S, Trojanoswki JQ, Lee VM (2001) Increased lipid peroxidation precedes amyloid plaque formation in an animal model of Alzheimer amyloidosis. J Neurosci 21, 4183-4187.

[4] Tamagno E, Parola M, Bardini P, Piccini A, Borghi R, Guglielmotto M, Santoro G, Davit A, Danni O, Smith MA, Perry G, Tabaton M (2005) Beta-site APP cleaving enzyme upregulation induced by 4-hydroxynonenal is mediated by stressactivated protein kinases pathways. J Neurochem 92, 628-636. 
[5] Coskun PE, Beal MF, Wallace DC (2004) Alzheimer's brains harbor somatic mtDNA control-region mutations that suppress mitochondrial transcription and replication. Proc Natl Acad Sci U S A 101, 10726-10731.

[6] Rui Y, Tiwari P, Xie Z, Zheng JQ (2006) Acute impairment of mitochondrial trafficking by beta-amyloid peptides in hippocampal neurons. J Neurosci 26, 10480-10487.

[7] Tan Z, Sun X, Hou FS, Oh HW, Hilgenberg LG, Hol EM, van Leeuwen FW, Smith MA, O'Dowd DK, Schreiber SS (2007) Mutant ubiquitin found in Alzheimer's disease causes neuritic beading of mitochondria in association with neuronal degeneration. Cell Death Differ 14, 1721-1732.

[8] Wang X, Su B, Zheng L, Perry G, Smith MA, Zhu X (2009) The role of abnormal mitochondrial dynamics in the pathogenesis of Alzheimer's disease. J Neurochem 109 Suppl 1, 153-159.

[9] Crouch PJ, Blake R, Duce JA, Ciccotosto GD, Li QX, Barnham KJ, Curtain CC, Cherny RA, Cappai R, Dyrks T, Masters CL, Trounce IA (2005) Copper-dependent inhibition of human cytochrome c oxidase by a dimeric conformer of amyloidbeta1-42. J Neurosci 25, 672-679.

[10] Gibson GE, Sheu KF, Blass JP, Baker A, Carlson KC, Harding B, Perrino P (1988) Reduced activities of thiamine-dependent enzymes in the brains and peripheral tissues of patients with Alzheimer's disease. Arch Neurol 45, 836-840.

[11] Manczak M, Anekonda TS, Henson E, Park BS, Quinn J, Reddy PH (2006) Mitochondria are a direct site of A beta accumulation in Alzheimer's disease neurons: implications for free radical generation and oxidative damage in disease progression. Hum Mol Genet 15, 1437-1449.

[12] Parker WD, Jr., Filley CM, Parks JK (1990) Cytochrome oxidase deficiency in Alzheimer's disease. Neurology 40, 13021303.

[13] Lustbader JW, Cirilli M, Lin C, Xu HW, Takuma K, Wang N, Caspersen C, Chen X, Pollak S, Chaney M, Trinchese F, Liu S, Gunn-Moore F, Lue LF, Walker DG, Kuppusamy P, Zewier ZL, Arancio O, Stern D, Yan SS, Wu H (2004) ABAD directly links Abeta to mitochondrial toxicity in Alzheimer's disease. Science 304, 448-452.

[14] Park HJ, Seong YM, Choi JY, Kang S, Rhim H (2004) Alzheimer's disease-associated amyloid beta interacts with the human serine protease HtrA2/Omi. Neurosci Lett 357, 63-67.

[15] Knott AB, Bossy-Wetzel E (2009) Nitric oxide in health and disease of the nervous system. Antioxid Redox Signal 11, 541554.

[16] Chen H, Detmer SA, Ewald AJ, Griffin EE, Fraser SE, Chan DC (2003) Mitofusins Mfn1 and Mfn2 coordinately regulate mitochondrial fusion and are essential for embryonic development. J Cell Biol 160, 189-200.

[17] Cipolat S, Martins de Brito O, Dal Zilio B, Scorrano L (2004) OPA1 requires mitofusin 1 to promote mitochondrial fusion. Proc Natl Acad Sci U S A 101, 15927-15932.

[18] Ishihara N, Eura Y, Mihara K (2004) Mitofusin 1 and 2 play distinct roles in mitochondrial fusion reactions via GTPase activity. J Cell Sci 117, 6535-6546.

[19] Labrousse AM, Zappaterra MD, Rube DA, van der Bliek AM (1999) C. elegans dynamin-related protein DRP-1 controls severing of the mitochondrial outer membrane. Mol Cell 4, 815-826.

[20] Meeusen S, DeVay R, Block J, Cassidy-Stone A, Wayson S, McCaffery JM, Nunnari J (2006) Mitochondrial innermembrane fusion and crista maintenance requires the dynamin-related GTPase Mgm1. Cell 127, 383-395.
[21] Olichon A, Baricault L, Gas N, Guillou E, Valette A, Belenguer P, Lenaers G (2003) Loss of OPA1 perturbates the mitochondrial inner membrane structure and integrity, leading to cytochrome c release and apoptosis. J Biol Chem 278, 7743-7746.

[22] Olichon A, Emorine LJ, Descoins E, Pelloquin L, Brichese L, Gas N, Guillou E, Delettre C, Valette A, Hamel CP, Ducommun B, Lenaers G, Belenguer P (2002) The human dynaminrelated protein OPA1 is anchored to the mitochondrial inner membrane facing the inter-membrane space. FEBS Lett $\mathbf{5 2 3}$, 171-176.

[23] Smirnova E, Griparic L, Shurland DL, van der Bliek AM (2001) Dynamin-related protein Drp1 is required for mitochondrial division in mammalian cells. Mol Biol Cell 12, 22452256.

[24] Bossy-Wetzel E, Barsoum MJ, Godzik A, Schwarzenbacher R, Lipton SA (2003) Mitochondrial fission in apoptosis, neurodegeneration and aging. Curr Opin Cell Biol 15, 706-716.

[25] Chan DC (2006) Mitochondria: dynamic organelles in disease, aging, and development. Cell 125, 1241-1252.

[26] Knott AB, Perkins G, Schwarzenbacher R, Bossy-Wetzel E (2008) Mitochondrial fragmentation in neurodegeneration. Nat Rev Neurosci 9, 505-518.

[27] Barsoum MJ, Yuan H, Gerencser AA, Liot G, Kushnareva Y, Graber S, Kovacs I, Lee WD, Waggoner J, Cui J, White AD, Bossy B, Martinou JC, Youle RJ, Lipton SA, Ellisman MH, Perkins GA, Bossy-Wetzel E (2006) Nitric oxide-induced mitochondrial fission is regulated by dynamin-related GTPases in neurons. EMBO J 25, 3900-3911.

[28] Wang X, Su B, Siedlak SL, Moreira PI, Fujioka H, Wang Y, Casadesus G, Zhu X (2008) Amyloid-beta overproduction causes abnormal mitochondrial dynamics via differential modulation of mitochondrial fission/fusion proteins. Proc Natl Acad Sci U S A 105, 19318-19323.

[29] Yuan H, Gerencser AA, Liot G, Lipton SA, Ellisman M, Perkins GA, Bossy-Wetzel E (2007) Mitochondrial fission is an upstream and required event for bax foci formation in response to nitric oxide in cortical neurons. Cell Death Differ 14, 462-471.

[30] Liot G, Bossy B, Lubitz S, Kushnareva Y, Sejbuk N, BossyWetzel E (2009) Complex II inhibition by 3-NP causes mitochondrial fragmentation and neuronal cell death via an NMDA- and ROS-dependent pathway. Cell Death Differ 16, 899-909.

[31] Cho DH, Nakamura T, Fang J, Cieplak P, Godzik A, Gu Z, Lipton SA (2009) S-nitrosylation of Drp1 mediates beta-amyloidrelated mitochondrial fission and neuronal injury. Science 324, 102-105.

[32] Lei SZ, Pan ZH, Aggarwal SK, Chen HS, Hartman J, Sucher NJ, Lipton SA (1992) Effect of nitric oxide production on the redox modulatory site of the NMDA receptor-channel complex. Neuron 8, 1087-1099.

[33] Ingerman E, Nunnari J (2005) A continuous, regenerative coupled GTPase assay for dynamin-related proteins. Methods Enzymol 404, 611-619.

[34] Jaffrey SR, Snyder SH (2001) The biotin switch method for the detection of S-nitrosylated proteins. Sci STKE 2001, pl1.

[35] Jaffrey SR, Erdjument-Bromage H, Ferris CD, Tempst P, Snyder SH (2001) Protein S-nitrosylation: a physiological signal for neuronal nitric oxide. Nat Cell Biol 3, 193-197.

[36] Yoon Y, Pitts KR, McNiven MA (2001) Mammalian dynaminlike protein DLP1 tubulates membranes. Mol Biol Cell 12, 2894-2905. 
[37] Shin HW, Takatsu H, Mukai H, Munekata E, Murakami K, Nakayama K (1999) Intermolecular and interdomain interactions of a dynamin-related GTP-binding protein, Dnm1p/Vps1p-like protein. J Biol Chem 274, 2780-2785.

[38] Zhu PP, Patterson A, Stadler J, Seeburg DP, Sheng M, Blackstone $C$ (2004) Intra- and intermolecular domain interactions of the C-terminal GTPase effector domain of the multimeric dynamin-like GTPase Drp1. J Biol Chem 279, 35967-35974.

[39] Mears JA, Hinshaw JE (2008) Visualization of dynamins. Methods Cell Biol 88, 237-256.

[40] Naylor K, Ingerman E, Okreglak V, Marino M, Hinshaw JE, Nunnari J (2006) Mdv1 interacts with assembled dnm1 to promote mitochondrial division. J Biol Chem 281, 2177-2183.

[41] Wang X, Su B, Lee HG, Li X, Perry G, Smith MA, Zhu X (2009) Impaired balance of mitochondrial fission and fusion in Alzheimer's disease. J Neurosci 29, 9090-9103.

[42] Lee HG, Casadesus G, Zhu X, Castellani RJ, McShea A, Perry G, Petersen RB, Bajic V, Smith MA (2009) Cell cycle reentry mediated neurodegeneration and its treatment role in the pathogenesis of Alzheimer's disease. Neurochem Int 54, 84-88.

[43] Chang CR, Blackstone C (2007) Drp1 phosphorylation and mitochondrial regulation. EMBO Rep 8, 1088-1089; author reply $1089-1090$

[44] Taguchi N, Ishihara N, Jofuku A, Oka T, Mihara K (2007) Mitotic phosphorylation of dynamin-related GTPase Drp1 participates in mitochondrial fission. $J$ Biol Chem 282, 1152111529.

[45] Herrup K, Neve R, Ackerman SL, Copani A (2004) Divide and die: cell cycle events as triggers of nerve cell death. $J$ Neurosci 24, 9232-9239.

[46] Bolanos JP, Peuchen S, Heales SJ, Land JM, Clark JB (1994) Nitric oxide-mediated inhibition of the mitochondrial respiratory chain in cultured astrocytes. J Neurochem 63, 910-916.

[47] Brown GC, Bolanos JP, Heales SJ, Clark JB (1995) Nitric oxide produced by activated astrocytes rapidly and reversibly inhibits cellular respiration. Neurosci Lett 193, 201-204.

[48] Brown GC, Cooper CE (1994) Nanomolar concentrations of nitric oxide reversibly inhibit synaptosomal respiration by competing with oxygen at cytochrome oxidase. FEBS Lett 356, 295-298.

[49] Shibuya A, Wada K, Nakajima A, Saeki M, Katayama K, Mayumi T, Kadowaki T, Niwa H, Kamisaki Y (2002) Nitration of PPARgamma inhibits ligand-dependent translocation into the nucleus in a macrophage-like cell line, RAW 264. FEBS Lett 525, 43-47.

50] Fuenzalida K, Quintanilla R, Ramos P, Piderit D, Fuentealba RA, Martinez G, Inestrosa NC, Bronfman M (2007) Peroxisome proliferator-activated receptor gamma up-regulates the Bcl-2 anti-apoptotic protein in neurons and induces mitochondrial stabilization and protection against oxidative stress and apoptosis. J Biol Chem 282, 37006-37015.

[51] Bossy-Wetzel E, Talantova MV, Lee WD, Scholzke MN, Harrop A, Mathews E, Gotz T, Han J, Ellisman MH, Perkins GA, Lipton SA (2004) Crosstalk between nitric oxide and zinc pathways to neuronal cell death involving mitochondrial dysfunction and p38-activated K+ channels. Neuron 41, 351-365.

[52] Bezprozvanny I, Mattson MP (2008) Neuronal calcium mishandling and the pathogenesis of Alzheimer's disease. Trends Neurosci 31, 454-463.

53] Han XJ, Lu YF, Li SA, Kaitsuka T, Sato Y, Tomizawa K, Nairn AC, Takei K, Matsui H, Matsushita M (2008) CaM kinase I alpha-induced phosphorylation of Drp1 regulates mitochondrial morphology. J Cell Biol 182, 573-585.

[54] Cereghetti GM, Stangherlin A, Martins de Brito O, Chang CR, Blackstone C, Bernardi P, Scorrano L (2008) Dephosphorylation by calcineurin regulates translocation of Drp1 to mitochondria. Proc Natl Acad Sci U S A 105, 15803-15808.

[55] Cribbs JT, Strack S (2007) Reversible phosphorylation of Drp1 by cyclic AMP-dependent protein kinase and calcineurin regulates mitochondrial fission and cell death. EMBO Rep 8, 939944.

[56] Casley CS, Canevari L, Land JM, Clark JB, Sharpe MA (2002) Beta-amyloid inhibits integrated mitochondrial respiration and key enzyme activities. $J$ Neurochem 80, 91-100.

[57] Casley CS, Land JM, Sharpe MA, Clark JB, Duchen MR, Canevari L (2002) Beta-amyloid fragment 25-35 causes mitochondrial dysfunction in primary cortical neurons. Neurobiol Dis 10, 258-267.

[58] Wang X, Su B, Fujioka H, Zhu X (2008) Dynamin-like protein 1 reduction underlies mitochondrial morphology and distribution abnormalities in fibroblasts from sporadic Alzheimer's disease patients. Am J Pathol 173, 470-482.

[59] Nakamura T, Lipton SA (2010) Redox regulation of mitochondrial fission, protein misfolding, synaptic damage, and neuronal cell death: potential implications for Alzheimer's and Parkinson's diseases. Apoptosis, in press. 